
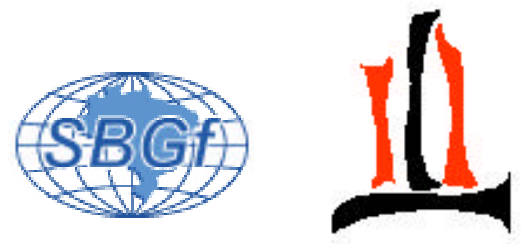

São Paulo 2004

\title{
Estudos crustais na área sismogênica de Porto dos Gaúchos/MT, baseados em Sísmica de Refração e Função do Receptor
}

Lucas V. Barros \& Cristiano C. Rancan

Observatório Sismológico, Universidade de Brasília <obsis@unb.br>

Copyright 2004, SBGf - Sociedade Brasileira de Geofísica

Este texto foi preparado para apresentação no I Simpósio de Geofísica da Sociedade Brasileira de Geofísica, São Paulo, 26-28 de setembro de 2004. Seu conteúdo foi revisado pela Comissão Tecno-cientifica do I SR-SBGf, mas não necessariamente representa a opinião da SBGf ou de seus associados. E proibida a reprodução total ou parcial deste material para propósitos comerciais sem prévia autorização da SBGt.

\section{Abstract}

It presents the results of crustal studies performed by Seismological Observatory of the University of Brasilia in Porto dos Gauchos/MT seismogenic zone located at the northern boundary of the Parecis intracratonic basin and at the southern portion of the Amazonian craton.

We used in this study the Seismic Refraction and Receiver Function techniques. In first case is presented a 1D velocity model, obtained from calibration of the Porto dos Gauchos/MT Local Seismograph Network and, in second, the crust thickness determined with Receiver Function applied to telesseismic data recorded by the Broadband Station JUAB.

\section{Introdução}

A área sismogênica de Porto dos Gaúchos/MT, uma das áreas sísmicas brasileiras mais importantes em termos de magnitude, $\left[m_{b}=6,2\right.$, em 31/03/1955 (Assumpção \& Suarez, 1988) e $m_{b}=5,1$ (Barros, 2004)] e, provavelmente, também em termos de frequência sísmica, com mais de 2500 sismos registrados apenas nos últimos seis anos, vem sendo estudada, com alguns resultados já divulgados (Barros et al., 2001 e Barros e Caixeta, 2003).

Neste trabalho são apresentados os resultados de estudos adicionais de estruturação crustal desenvolvidos, usando as técnicas de Sísmica de Refração (SR) e da Função do Receptor (FR). No primeiro caso é apresentado o modelo de velocidades 1-D, obtido a partir da análise dos registros de duas explosões de calibração feitas no interior da Rede Sismográfica Local de Porto dos Gaúchos (Barros e Caixeta, 2003). No segundo, são apresentados os resultados dos estudos feitos com a técnica FR, usando-se dados telessísmicos da Estação de Banda Larga JUAB, instalada a leste da cidade de Juara/MT.

Nos estudos com a técnica SR determinou-se um pacote vulcano-sedimentar de 2,3 km de espessura e um limite crosta superior-crosta inferior a $17,3 \mathrm{~km}$ na região de Porto dos Gaúchos. Com a técnica FR determinou-se uma profundidade de $36 \mathrm{~km}$ para a descontinuidade de Moho na região de Juara/MT.

A área em estudo situa-se no centro norte do estado do Mato Grosso, incluindo terrenos do sul do Cráton Amazônico e da extremidade norte da Bacia dos Parecis, a qual, juntamente com as bacias do Solimões e do
Paraná, definem o conjunto de bacias Paleozóicas brasileiras adjacentes à depressão subandina (Siqueira, 1989).

\section{Metodologias empregadas no estudo}

Foram empregadas duas técnicas geofísicas: Sísmica de Refração (SR) e Função do Receptor (FR). A aplicação da SR em estudos crustais se fundamenta no fato de que as ondas sísmicas irradiadas a partir da fonte se constituem em um "veículo" através do qual as informações sobre a estruturação geológica de um meio acamadado chegam a diversos receptores colocados na superfície do terreno, pois as condições de propagação das ondas dependem fundamentalmente das propriedades elásticas do meio.

Por esta razão, a estrutura de velocidades, i. é, as espessuras das camadas e as respectivas velocidades das ondas compressionais $P$ podem ser determinadas em um experimento geofísico com fonte controlada por meio de gráficos das distâncias da fonte sísmica æ̀ diversas estações de registro, pelos seus respectivos tempos de percurso.

A Função do Receptor é uma série temporal obtida de sismogramas de estações sismográficas triaxiais, que contêm informações de como as estruturas crustais respondem à passagem das ondas sísmicas sob 0 receptor. O modelamento da amplitude e do tempo dessa série temporal pode fornecer valiosas informações sobre a geologia das estruturas sob a estação (Ammon, 1991).

\section{Função do Receptor}

A técnica da Função do Receptor está baseada no princípio segundo o qual uma onda $\mathrm{P}$ telessísmica $(\Delta \geq$ $30^{\circ}$ ), ao incidir sobre uma descontinuidade brusca, como é o caso da Moho, tem a maior parte de sua energia convertida em onda $S$, fase $P_{S}$ ( $P$ convertida em $S$ ). Identificando-se esta fase na Função do Receptor, é possível determinar a profundidade da descontinuidade correspondente.

Uma onda sísmica, na forma como se apresenta no sismograma, contém informações da fonte (mecanismo gerador no foco), do caminho de propagação da fonte ao receptor (interação com o meio) e do sismógrafo (amplificação dependente da frequência). Uma importante informação adicionada à onda sísmica diz respeito à forma como esta interage com as estruturas geológicas nas vizinhanças do receptor, conhecida como efeitos locais, os quais são dependentes, dentre outros, de características das descontinuidades abaixo da estação, tais como: contraste de velocidades e espessuras das camadas. 
O objetivo da técnica da Função do Receptor é isolar esses efeitos, de modo a permitir inferências sobre as estruturas geológicas que afetam as ondas sísmicas embaixo das estações sismográficas. Portanto, a aplicação da técnica FR consiste, resumidamente, de duas etapas: determinação da função do receptor e inversão da função do receptor para encontrar um modelo estrutural correspondente.

As três componentes do movimento do chão [vertical, $\mathrm{Z}(\mathrm{t})$, radial, $\mathrm{R}(\mathrm{t})$ e tangencial $\mathrm{T}(\mathrm{t})$ ] registradas numa estação podem, teoricamente, ser representadas pelas equações:

$$
\begin{aligned}
& Z(t)=h(t) * s(t) * e_{v}(t) \leftrightarrow Z(\omega)=H(\omega) \cdot S(\omega) \cdot E_{v}(\omega) \\
& R(t)=h(t) * s(t) * e_{r}(t) \leftrightarrow R(\omega)=H(\omega) \cdot S(\omega) \cdot E_{r}(\omega) \\
& T(t)=h(t) * s(t) * e_{t}(t) \leftrightarrow T(\omega)=H(\omega) \cdot S(\omega) \cdot E_{t}(\omega)
\end{aligned}
$$

onde $\mathrm{h}(\mathrm{t})$ é a resposta impulsional do sismógrafo, $\mathrm{s}(\mathrm{t})$ é a função temporal da fonte e $e_{v}(t), e_{r}(t)$ e $e_{t}(t)$ são, respectivamente, as respostas temporais do site (resposta das estruturas abaixo do receptor) nas componentes vertical, radial e transversal. As equações 1, 2 e 3 (lado direito) resultaram da aplicação do teorema da convolução (Oppenheim \& Schafer, 1975), onde $\omega(2 \pi f)$ é a frequência angular.

Para uma onda $P$ telessísmica com incidência quase vertical sob a estação, a componente $e_{v}(t)$ é um pico inicial de maior amplitude, seguido por alguns picos menores resultantes de reverberações e fases convertidas. Considerando-se que toda energia está concentrada no pico inicial, a componente $e_{v}(t)$ pode ser aproximada por uma função delta,

$\mathrm{e}_{\mathrm{v}}(\mathrm{t}) \approx \delta(\mathrm{t}) \leftrightarrow \mathrm{E}_{\mathrm{v}}(\omega)=1$

Substituindo (4) em (1), temos:

$\mathrm{Z}(\omega)=\mathrm{H}(\omega) \cdot \mathrm{S}(\omega)$

Levando esse resultado nas equações 2 e 3, lado direito, temos:

$E_{R}(\omega)=\frac{R(\omega)}{H(\omega) \cdot S(\omega)} \approx \frac{R(\omega)}{Z(\omega)} \leftrightarrow E_{R}(t)=\int_{-\infty}^{\infty} E_{R}(\omega) e^{j \omega t} d \omega$
$E_{T}(\omega)=\frac{T(\omega)}{H(\omega) \cdot S(\omega)} \approx \frac{T(\omega)}{Z(\omega)} \leftrightarrow E_{T}(t)=\int_{-\infty}^{\infty} E_{T}(\omega) e^{j \omega t} d \omega$

onde $E_{R}(\omega)$ e $E_{T}(\omega)$ são as transformadas de Fourier das FRs radial e transversal, respectivamente.

$A F R$ radial $\left[E_{R}(t)\right]$ é a mais importante, pois, como a onda $P$ vibra na direção radial, a amplitude da fase $P_{S}$ é mais pronunciada na FR radial. A Figura 1 apresenta um diagrama de raios sísmicos para uma FR radial (a) e as principais fases convertidas para a onda $\mathrm{P}$ em (b).

\section{Deconvolução da Função do Receptor}

As deconvoluções, equações 6 e 7, são realizadas no domínio da freqüência, na forma

$$
E_{R}(\omega)=\frac{R(\omega) Z *(\omega)}{Z(\omega) Z^{*}(\omega)}=\frac{R(\omega) Z *(\omega)}{\operatorname{Re}^{2} Z(\omega)+\operatorname{lm}^{2}[Z(\omega)]}
$$

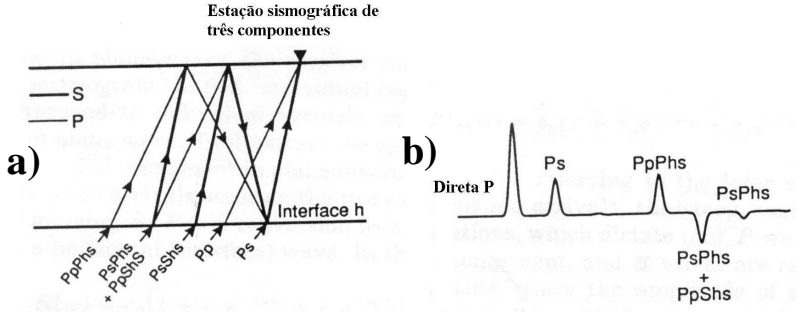

Figura 1 - Diagrama de raios sísmicos da função do receptor. $\mathrm{Na}$ parte a tem-se o diagrama de raio simplificado, mostrando as principais conversões da onda $P$ em ondas $S$ que consta da Função do Receptor radial para uma camada sobre um semiespaço. Na parte $\underline{b}$ é apresentada a forma de onda correspondente ao diagrama do lado, exceto para a primeira chegada (onda $P$ direta). As letras maiúsculas denotam caminho de raio para cima, letras minúsculas denotam caminho de raio para baixo e $\underline{h}$ indica a reflexão na interface de profundidade $\underline{h}$.

Na prática, $E_{R}(\omega)$ não pode ser determinada na forma da equação 8 , pois pequenos valores no denominador causam problemas numéricos nos cálculos. Alternativamente, Langston (1979) propôs uma solução para este problema, introduzindo um artifício, na forma da equação 9, para evitar divisão por zeros. Assim:

$E_{R}(\omega)=\frac{R(\omega) Z *(\omega)}{\phi(\omega)} G(\omega)$

onde $\phi(\omega)=\max \left\{Z(\omega) Z^{*}(\omega), c \cdot \max \left[Z(\omega) Z^{*}(\omega)\right]\right\}$

A constante $\underline{\mathbf{c}}$, conhecida como parâmetro nível d'água, (NG) determina a amplitude mínima permitida no denominador da equação 8. $G(\omega)$ é um filtro Gaussiano, sem distorção de fase e sem lóbulos laterais, dado por:

$G(\omega)=\xi \exp \left(\frac{-\omega^{2}}{4 \alpha^{2}}\right)$

A definição de $E_{T}(\omega)$ é semelhante; basta trocar $R(\omega)$ por $\mathrm{T}(\omega)$ na equação 9 . Os procedimentos adotados neste trabalho foram baseados em Ammon (1991).

\section{Aplicação da Técnica FR aos dados de JUAB}

A Estação de banda larga JUAB, cujos dados foram utilizados neste trabalho, situa-se no distrito de Jaú, município de Juara/MT, um pouco fora da Bacia dos Parecis, instalada sobre afloramento granítico da porção central do cratón Amazônico (Fig. 2).

\section{Geologia regional}

A área em estudo (destacada na Figura 2) inclui terrenos pré-cambrianos e fanerozóicos. Os terrenos précambrianos são rochas constituintes do Cráton Amazônico, sul da Província geocronológica Rio-Negro/ Juruena, na região do Gráben dos Caiabis, estrutura de direção WNW- ESE. Os terrenos fanerozóicos dizem respeito à Bacia dos Parecis, que situa-se no centrooeste do Brasil, alongada na direção E-W, e ocupa uma área de aproximadamente $400.000 \mathrm{Km}^{2}$ e distribui-se pelos estados de Rondônia e Mato Grosso. A coluna estratigráfica da Bacia inclui unidades paleozóicas, mesozóicas e cenozóicas, cuja evolução esteve sob forte influência da tectônica nas margens pretéritas do 
continente sul-americano. A partir da integração tectonoestratigráfica pode-se definir que a evolução da Bacia dos Parecis iniciou-se como uma bacia do tipo rift na Era Paleozóica, com sedimentação sujeita principalmente a controles eustáticos. Após o Devoniano, a bacia passou a um regime de sinéclise, com forte influência tectônica, refletida pela mudança progressiva dos depocentros (Siqueira, 1989).

\section{Levantamentos aerogeofísicos na área}

A Fig. 2 é um mapa de anomalia Bouger levantado pela Petrobrás para toda a Bacia dos Parecis. A região situase num alto gravimétrico, indicando uma menor espessura do pacote sedimentar. Neste local, de acordo com Barros \& Caixeta (2003), o embasamento está a uma profundidade média de 2,3 km. Também é visível o contraste de densidades, melhor evidenciado no zoom da Fig. 2.

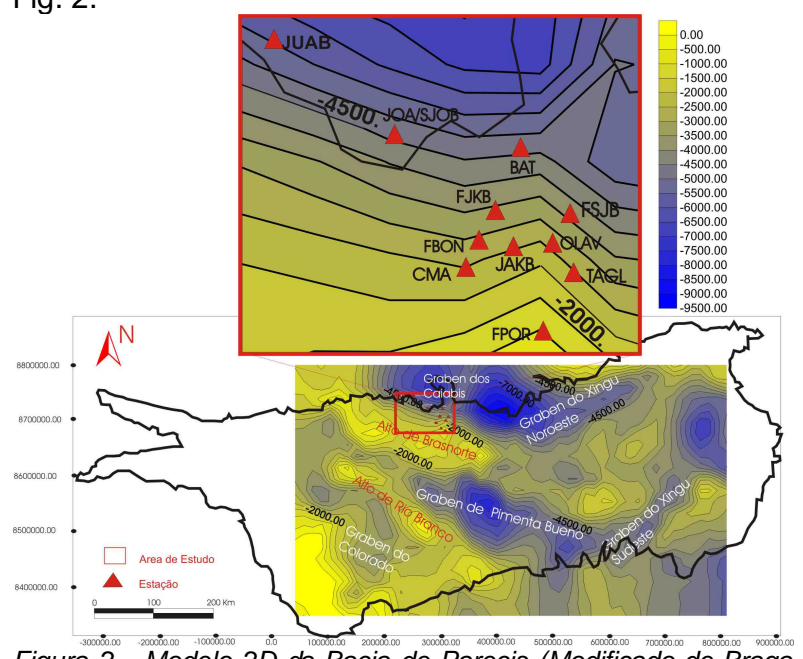

Figura 2 - Modelo $2 D$ da Bacia de Parecis (Modificado de Braga et al., 1995).

Dados de aeromagnetometria levantados pela Petrobrás indicam também um forte contraste magnético na borda da Bacia, o que era de se esperar, pois a extremidade da Bacia coincide com uma zona de transição entre rochas da formação Caiabis e rochas da formação Dardanelos.

\section{Dados para a Função do Receptor}

Os dados utilizados para a Função do Receptor estão apresentados na Tabela 1.

Tabela 1 - Telessismos usados na FR.
\begin{tabular}{|c|c|c|c|c|c|c|c|c|c|c|c|}
\hline $\boldsymbol{N}$ & Ano & Dia & H:m:s $:$ Lat & Long & $\boldsymbol{h}(\mathbf{k m})$ & $\boldsymbol{m}_{\boldsymbol{b}}$ & $\boldsymbol{m}_{\boldsymbol{s}}$ & $\boldsymbol{\Delta}\left(\mathbf{\circ}^{\circ}\right)$ & $\left.\boldsymbol{A z} \mathbf{(}^{\circ}\right)$ & $\boldsymbol{P ( \mathbf { s } ^ { \circ } )}$ \\
\hline 1 & 1999 & 277 & $13: 57: 38,7$ & $-10,708$ & $-75,666$ & 33 & 5,5 & 5,0 & 18,078 & 269,8 & 12,2 \\
\hline 2 & 1999 & 338 & $17: 06: 50,8$ & $-28,452$ & $-71,030$ & 33 & 5,5 & 5,1 & 21,452 & 214,9 & 10,7 \\
\hline 3 & 1999 & 324 & $21: 52: 51,1$ & $-30,790$ & $-71,836$ & 33 & 5,1 & 4,8 & 23,708 & 212,5 & 9,14 \\
\hline 4 & 1999 & 272 & $18: 01: 31,5$ & $-30,815$ & $-71,966$ & 33 & 5,5 & 5,2 & 23,797 & 212,7 & 9,13 \\
\hline 5 & 1999 & 335 & $19: 23: 07,6$ & 17,894 & $-82,403$ & 10 & 5,8 & 5,7 & 38,117 & 379,0 & 8,42 \\
\hline 6 & 1999 & 273 & $16: 31: 16,6$ & 16,197 & $-96,872$ & 63 & 6,6 & 0 & 47,726 & 304,1 & 7,74 \\
\hline 7 & 1999 & 316 & $16: 57: 19,7$ & 40,730 & $-31,122$ & 10 & 6,3 & 7,5 & 96,002 & 49,8 & 4,51 \\
\hline
\end{tabular}

\section{Resultados}

Com a aplicação da SR aos dados de duas explosões de calibração, determinou-se o modelo de velocidades da Tabela 2 (Barros e Caixeta, 2003). A Fig. 3 mostra as FRs radiais obtidas para os telessismos da Tabela 1 e a Fig. 4, as duas FRs selecionadas para o empilhamento.
Tabela 2 - Modelo de velocidades obtido por $S R\left(v_{P} / v_{S}=1,74\right)$.

\begin{tabular}{|c|c|c|c|c|c|}
\hline Camada & Espessura & $\mathbf{V p}(\mathbf{k m} / \mathbf{s})$ & $\mathbf{V s}(\mathbf{k m} / \mathbf{s})$ & $\boldsymbol{\rho}\left(\mathbf{g r} / \mathbf{c m}^{\mathbf{3}}\right)$ & $\boldsymbol{\sigma}$ \\
\hline 1 & 0,000 & 3,800 & 2,184 & 2,650 & 0,250 \\
\hline 2 & 0,300 & 5,900 & 3,390 & 2,700 & 0,250 \\
\hline 3 & 2,000 & 6,200 & 3.563 & 2,750 & 0,250 \\
\hline 4 & 15,000 & 6,800 & 3.908 & 2,780 & 0,250 \\
\hline 5 & $\infty$ & 8,200 & 4,713 & 2,800 & 0,250 \\
\hline
\end{tabular}

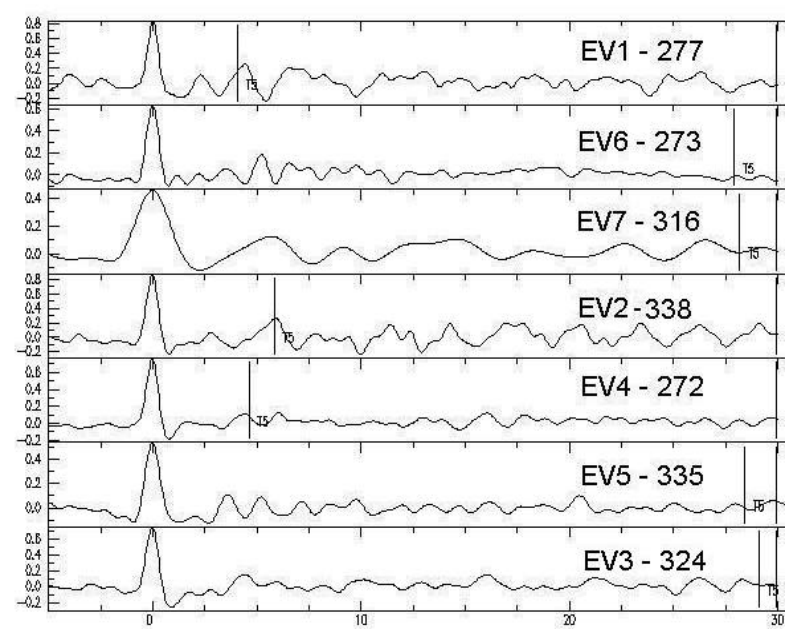

Figura 3 - Funções do Receptor radiais para os telessismos: 1 277$, 2) 338,3$) 324,4) 272,5) 335,6) 273$ e 7) 316 da Tabela 1.
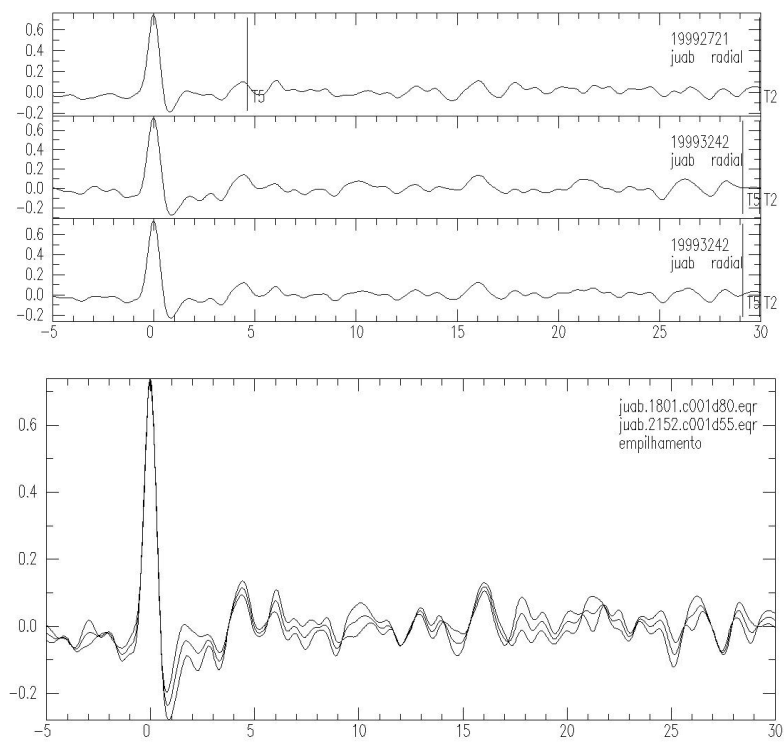

Figura 4 - Função do receptor radial [Superior: evento 1999/344, delta $=23.7, A z=212.5$ e $p=9.14$; central evento 1999/272, delta $=23.8, A z=212.7$ e $p=9.13$; inferior: empilhamento (RF1 $+R F 2) / 2]$ e resultado do empilhamento das funções do receptor correspondentes (àdireita).

As diferenças de tempo de percurso das fases $\mathrm{Ps}$ e $\mathrm{P}$ ( $\mathrm{t}_{\mathrm{ps}}$ - $t_{p}$ ) é dependente da espessura média da crosta, das velocidades médias $\left(V_{P}\right.$ e $\left.V_{S}\right)$ e da razão $V_{P} / V_{S}$ (Zandt et al., 1995). Essa diferença para dados telessísmicos é dada por:

$$
\begin{aligned}
& t_{p s}-t_{p}=h\left[\left(V_{s}^{-2}-p^{2}\right)^{1 / 2}-\left(v_{p}^{-2}-p^{2}\right)^{1 / 2}\right] \\
& \text { onde } h=\left(t_{P S}-t_{P}\right) /\left(v_{S}^{-2}-p^{2}\right)^{1 / 2}-\left(V_{P}^{-2}-p^{2}\right)^{1 / 2}
\end{aligned}
$$

A diferença de tempo de percurso (tps - tp) é de 4,5s, o parâmetro do raio médio é igual a 0,0829 e as 
velocidades médias do modelo adotado são $V_{P}=6,35$ e $V_{S}=3,65$. Levando esses valores na equação acima, temos que a profundidade da Moho é de $36 \mathrm{~km}$.

Tabela 3 - Dados para a equação 13.
\begin{tabular}{|c|c|c|c|c|c|c|c|c|}
\hline$\#$ & tps-tp & $\mathbf{D}^{2}$ & $\mathbf{V s}^{-2}$ & $\mathbf{p}^{2}$ & $\left(\mathbf{V s}^{-2}-\mathbf{p}^{2}\right)^{1 / 2}$ & $\mathbf{V}^{-2}$ & $\left(\mathbf{V v}^{-2}-\mathbf{p}^{2}\right)^{1 / 2}$ & $\mathbf{H}(\mathbf{k m})$ \\
\hline 1 & 4,5 & 0,012037 & 0,07506 & 0,012037 & 0,251044 & 0,024800 & 0,112974 & 32,59 \\
\hline 2 & 5,0 & 0,009259 & 0,07506 & 0,009259 & 0,256517 & 0,024800 & 0,124664 & 37,92 \\
\hline 3 & 4,6 & 0,006756 & 0,07506 & 0,006756 & 0,261351 & 0,024800 & 0,134328 & 36,21 \\
\hline 4 & 5,4 & 0,006741 & 0,07506 & 0,006741 & 0,261379 & 0,024800 & 0,134383 & 42,52 \\
\hline 5 & 5,0 & 0,005733 & 0,07506 & 0,005733 & 0,263299 & 0,024800 & 0,138082 & 39,93 \\
\hline 6 & 5,0 & 0,004845 & 0,07506 & 0,004845 & 0,264982 & 0,024800 & 0,141263 & 40,41 \\
\hline 7 & 5,4 & 0,001645 & 0,07506 & 0,001645 & 0,270952 & 0,024800 & 0,152168 & 45,46 \\
\hline
\end{tabular}

\section{Discussão e conclusões}

A técnica da Função do Receptor é uma importante ferramenta para se determinar a estrutura crustal usando dados de estações triaxiais. Foram calculadas 7 FR utilizando-se dados de telessismos com magnitudes $(\mathrm{mb})$ variando entre 5.0 e 6.6 , com distâncias epicentrais $(\Delta)$ maiores que $18^{\circ}$ e menores que $96^{\circ}$. Apesar de poucos dados, foi possível obter uma espessura de crosta de 36 $\mathrm{km}$, por meio do empilhamento de duas funções.

É importante ressaltar que essa técnica exige mais clareza da fase $P_{S}$, pois os resultados são muito sensíveis a este parâmetro. É necessário também utilizar dados de telessismos mais distantes, bem como testar outros valores de parâmetros N-G e filtros Gaussianos, com diferentes freqüências de corte. Utilizou-se um único valor NG $(0,001)$ e um parâmetro fixado em 3 .

O modelo 1-D e o resultado da FR foram integrados à geologia na interpretação crustal da área (Fig. 5). A Estação JUAB está situada sobre rochas granitognáissicas, enquanto que as estações utilizadas para o modelo 1-D estão sobre rochas sedimentares e vulcanosedimentares. Por isto, o embasamento situa-se a profundidades diferentes em JUAB e na área da Rede Sismográfica Local de Porto dos Gaúchos.

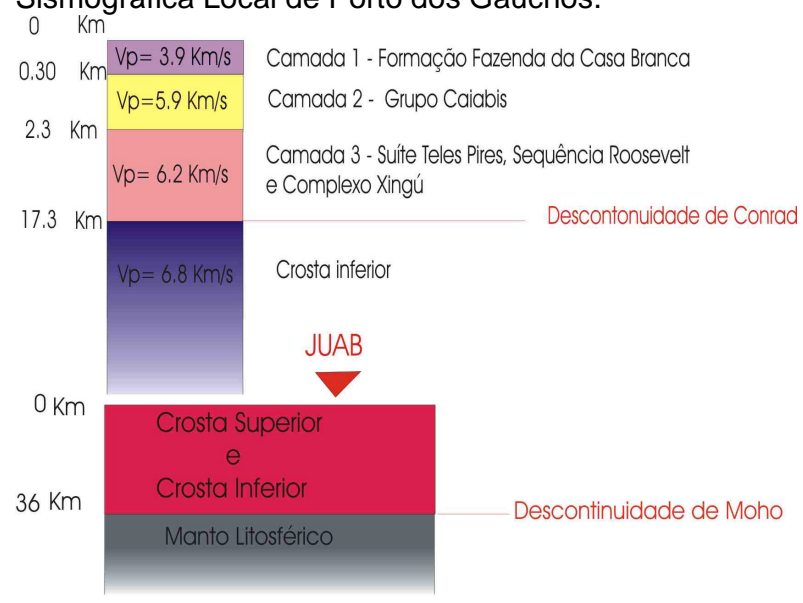

Figura 5 - Modelos 1-D e da Função do Receptor.

A velocidade $V_{P}=3.9 \mathrm{Km} / \mathrm{s}$ foi obtida para profundidades de 0 a $300 \mathrm{~m}$ e pode ser reflexo de rochas sedimentares, como arenitos, folhelhos e conglomerados (camada 1), presentes na Formação Fazenda da Casa Branca. De 300 a $2300 \mathrm{~m}, \mathrm{~V}_{\mathrm{p}}=5.9 \mathrm{Km} / \mathrm{s}$, associada a rochas supracrustais mesoproterozóicas do Grupo Caiabis, responsável pelo aumento na velocidade das ondas $P$, devido æ̀s intercalações basálticas e diques de diabásio da Formação Arinos (camada 2). A velocidade de $V_{p}=6.2$ $\mathrm{Km} / \mathrm{s}$ foi obtida experimentalmente para um conjunto rochoso com $15 \mathrm{Km}$ de espessura, cuja base encontra-se a $17.300 \mathrm{~m}$ de profundidade (camada 3). Essa camada apresenta velocidade média de rochas gnáissicas, com composição granítica a tonalítica, comum em áreas cratônicas. Abaixo de $17.3 \mathrm{Km}$ de profundidade a velocidade das ondas $P$ aumenta para $6.82 \mathrm{Km} / \mathrm{s}$, comum em migmatitos e milonitos. Essa mudança de velocidade provavelmente reflete a descontinuidade de Conrad. A profundidade de $36 \mathrm{Km}$ é interpretada como a descontinuidade de Moho, pontualmente abaixo da Estação JUAB. O modelo final para a área da rede sismográfica local é relativamente concordante com o de Braga \& Siqueira (1995). No entanto, a FR discorda desses dados, uma vez que a Estação JUAB situa-se diretamente sobre o embasamento (Granito São Romão), aflorante na área.

\section{Agradecimentos}

Os autores agradecem ao Dr. L. F. S. Braga pela cessão dos dados do modelo 2D da Bacia e ao Dr. George S. L. A. de França pelo ensinamento da técnica FR.

\section{Referências bibliográficas}

ASSUMPÇÃO, M. \& SUÁREZ, G. (1988). Source mechanisms of moderate-size earthquakes and stress orientation in mid-plate S. America. Geop. J., 92.

AMMON, C. J. (1991). An overview of the ReceiverFunction Analysis. http://eqseis.geosc.psu.edu/

AMMON, C. J. (1991). The isolation of receiver effects from telesseismic $P$ waveforms, Bull. Seism. Soc. Am., vol. 81, no 6, pp. 2504-2510.

BARROS, L.V., MARZA, V., CAIXETA, D.F., \& CARVALHO, J.M. (2001) Seismic Sequence in Porto dos Gaúchos/MT - Brazil After March/1998 Mainshock: Preliminary results: Submited to the $6^{\text {th }}$ Intern. Congr. of the Brazilian Geop. Society, $4 p$.

BARROS, L. V. \& CAIXETA, D.F. (2003). OneDimensional Multilayer Velocity Model for Porto dos Gauchos/MT. 8 SBGf, de 14 a 18/09/2003, 6pp.

BRAGA, L.F.S. \& SIQUEIRA, L. P. (1995). Three dimensional gravity modelling of the basement topography beneath Parecis Basin, Brazil, constrained by spectral estimates of depth to magnetic sources. $5^{\text {th }}$ Latin Amer. Petr. Cong, Rio de Janeiro, Brazil.

LANGSTON, C. A. (1979). Structure under Mount Rainier, Washington, inferred from telesseismic body waves, J. Geophys. Res., 84, 4749-4762.

OPPENHEIM, \& SCHAFER (1975). Digital Signal Processing, Prentice-Hall, 585pp.

OWENS, T. J., ZANDT, G. TAYLOR, S. R. (1984). Seismic evidence for an ancient rift beneath the Cumberland Plateau, Tennessee: A detailed analysis of broadband teleseismic P waveforms, J. Geophys. Res., 89, 7783-7795, 1984.

SIQUEIRA, L. P. (1989). Bacia dos Parecis. Geociências PETROBRAS, 3(112):3-16.

ZANDT, G., MYERS, S. C. \& WALLACE, T. C. (1995). Crust and mantle structure across the Basin and Range - Colorado plateau at $37^{\circ} \mathrm{N}$ latitude and implications for Cenozoic extensional mechanism, J. Geophys. Res. 100, 10.529-10.548. 